\title{
A family-oriented therapy program for youths with substance abuse: long-term outcomes related to relapse and academic or social status
}

This article was published in the following Dove Press journal:

Neuropsychiatric Disease and Treatment

30 March 2016

Number of times this article has been viewed

\author{
Liang-Jen Wang' \\ Shing-Fang Lu' \\ Mian-Yoon Chong ${ }^{2}$ \\ Wen-Jiun Chou' \\ Yu-Lian Hsieh' \\ Tung-ning Tsai' \\ Ching Chen ${ }^{2}$ \\ Yi-Hsuan Lee'
}

'Department of Child and Adolescent Psychiatry, ${ }^{2}$ Department of Psychiatry, Kaohsiung Chang Gung Memorial Hospital, Chang Gung University College of Medicine, Kaohsiung, Taiwan
Correspondence: Liang-Jen Wang Department of Child and Adolescent Psychiatry, Kaohsiung Chang Gung Memorial Hospital, 123 Ta-Pei Road, Niao-Sung District, Kaohsiung City 8330I, Taiwan

Tel $+886773|7| 23$ ext 8907

Fax +88677326817

Email wangliangjen@gmail.com
Objective: The abuse of illegal substances by youths in Taiwan has become a major public health issue. This study explores the outcomes (relapse rate and academic or social status) of a family-oriented therapy program conducted for substance-using youths who were referred by a judge to participate in it.

Methods: The present study includes 121 participants categorized into three groups: 36 youths underwent a weekly ten-session outpatient motivational enhancement psychotherapy (MEP) group program; 41 youths participated in a program that combined the aforementioned MEP program with an additional weekly ten-session parenting skill training (PST) program for their guardians (MEP + PST group); and 44 adolescents who received standard supervision by the court served as the control group. All participants were followed-up for a maximum of 2 years.

Results: Of the 121 participants (mean age: $16.1 \pm 1.1$ years), 33.1\% relapsed into substance use during the follow-up period. The probability of relapse did not differ significantly between the MEP group (36.1\%) and the control group (40.9\%), but the youths in the MEP + PST group $(22.0 \%)$ were at a lower risk of relapse than the control group participants (adjusted hazard ratio $=0.48,95 \%$ confidence interval $[\mathrm{CI}]=0.21-1.09$ ). By the end of the study follow-up period, participants in both the MEP group and the MEP + PST group were more likely to be attending school (MEP group: adjusted odds ratio $[\mathrm{aOR}]=6.61,95 \% \mathrm{CI}=1.60-27.35$; $\mathrm{MEP}+\mathrm{PST}$ group: $\mathrm{aOR}=8.57,95 \% \mathrm{CI}=1.94-37.82$ ) or employed (MEP group: $\mathrm{aOR}=7.75,95 \% \mathrm{CI}=1.95-30.75$; MEP + PST group: $\mathrm{aOR}=7.27,95 \% \mathrm{CI}=1.76-29.97$ ), when compared to the control group.

Conclusion: This study revealed that a family-oriented treatment approach may be a more effective option for preventing youths' relapsing into substance abuse. In comparison to individuals who received standard supervision by the court, those who received MEP experienced a better school attendance or social outcome over the follow-up period.

Keywords: substance abuse, psychotherapy, family, juvenile delinquency, longitudinal study

\section{Introduction}

High rates of youths abusing substances have become a serious public health issue throughout the world. ${ }^{1,2}$ In the US alone, up to $75.6 \%$ of youths under the age of 18 have admitted to using an addictive substance (such as cigarettes, alcohol, marijuana, and/or cocaine) at least once. ${ }^{3,4}$ Substance abuse among Taiwan's adolescents has also increased recently, ${ }^{5}$ with ketamine, ecstasy, and methamphetamine being the most popular illicit drugs among Taiwan's substance-abusing youth. ${ }^{6-8}$ Substance abuse can result in severe and harmful complications in youths throughout their entire life, including physical illnesses, cognitive deficits, and impairments related to academic or occupational function, making them a social burden and even causing death..$^{9,10}$ 
Therefore, helping substance-abusing youths, as well as their families, is critical in order to prevent, detect, and treat such abuse. Complex interplay of psychosocial context is involved in the underlying mechanism of substance use among adolescents, thus, varieties of psychosocial intervention continue to be the most common form of treatment. ${ }^{11,12}$

Several treatment options (eg, multidimensional family therapy, motivational enhancement therapy, and cognitive behavior therapy) appear to be well-established methods for intervening in substance abuse. ${ }^{13,14}$ Of these, motivational enhancement psychotherapy (MEP) is a widely used therapeutic approach for drug-addicted youths. ${ }^{15} \mathrm{MEP}$ provides a nonconfrontational environment that can help youths discover the various aspects of their drug use patterns, as well as an atmosphere that actively encourages them to engage in treatment to ultimately end the substance abuse. ${ }^{16}$ Furthermore, a parent is one of the most powerful formative influences of adolescents and a role model with regards to attitudes about health, behavioral norms, and social boundaries. ${ }^{17}$ Adolescents raised in a family in which their caregivers had poor parenting skills may be at a higher risk for substance abuse and subsequent relapses. ${ }^{18-20}$ To further improve family function, a successful therapy program for substance-abusing youths should also include a parenting skill training (PST) program for such youths' caregivers. ${ }^{21,22}$ Previous studies have shown that group work based on the MEP or PST principle is a viable method for treating these young patients. ${ }^{23,24}$

According to the Narcotics Hazard Prevention Act and Juvenile Accident Act in Taiwan, illegal substance use by youths is generally categorized as juvenile delinquency. Adolescents caught using illicit drugs can be sentenced to probation, receive reformatory education, or undergo detoxification. ${ }^{25}$ However, a regular method of psychosocial intervention for substance-abusing adolescents has yet to be standardized in Taiwan. Therefore, in 2011, Taiwan's Kaohsiung Juvenile and Family Court and Kaohsiung Chang Gung Memorial Hospital joined forces to develop a group treatment program for substance-abusing juveniles based on the MEP principle. The judges sentenced underage individuals who had been arrested for substance use to participate in a hospital-run treatment program. In 2013, the treatment program was revised and became a combination of an MEP program for substance-using adolescents and a PST program for their caregivers. The treatment had the following goals for its participants: prevention of substance abuse relapse, improvement of their family function, and further assistance for better academic and/or social results.

The current study aims to explore the outcomes (relapse rate and academic or social standing) of the substance-using youths after they complete the aforementioned treatment program. We propose that youths participating in a familyoriented treatment program (that combines MEP and PST) achieve improved outcomes when compared to both those undergoing MEP alone and those without any specific intervention.

\section{Methods}

\section{Study participants}

This study was approved by the Institutional Review Board at Chang Gung Memorial Hospital. Participants' information were provided by the Taiwan's Kaohsiung Juvenile and Family Court. Patient records/information was anonymized and de-identified prior to analysis, and the need for written informed consent was waived by the Institutional Review Board. This research is classified as a prospective, nonrandomized, open-label study that was performed to assess the effects of MEP and PST in the treatment of substance-using adolescents. The inclusion criteria for participants of this study were: 1) adolescents with substance use; 2) age ranging from 13 to 18 years; and 3) being eligible for the treatment program assigned by the Taiwan's Kaohsiung Juvenile and Family Court. The participants were categorized into three different groups based on their intervention method.

The MEP group $(n=36)$ consisted of youths who were recruited between July 2011 and December 2012 to participate in the MEP program. They were referred from Taiwan's Kaohsiung Juvenile and Family Court and were sentenced to participate in a weekly ten-session outpatient treatment program based on the motivation enhancement principle at Kaohsiung Chang Gung Memorial Hospital.

The MEP + PST group $(n=41)$ consisted of youths who were recruited between January 2013 and August 2014 to participate in a treatment program that fused MEP and PST approaches. The youths in the MEP + PST group participated in a weekly ten-session outpatient MEP program, just like the MEP group. However, in addition to this, these youths' caregivers were referred to simultaneously take part in a weekly ten-session outpatient PST program at Kaohsiung Chang Gung Memorial Hospital.

The control group $(n=44)$ consisted of the adolescents who were not referred to or who refused to participate in either the MEP or MEP + PST program, or whose caregivers could not attend the PST program. They were recruited between July 2011 and August 2014 and received only standard supervision by the protection officers in Taiwan's Kaohsiung Juvenile and Family Court. The protection officers provided the adolescents with moral education, as well as counseling in their work or studies. 


\section{MEP program for adolescents}

The participating youths had to attend one session a week for 10 weeks of a group program for relapse prevention based on motivational enhancement ideas and led by two experienced psychologists from the hospital. Each session had approximately eight participants and lasted for 120 minutes with a 10-minute break. The goal of the sessions was to arouse the youths' motivation for change by discovering both their reasons for using and reasons for abstaining. The session's principal method was feedback, using reflection and questions to prompt self-motivational statements. The MEP program aimed at identifying the conditions in which youths found themselves at a higher risk for substance abuse, as well as improving their motivation for abstaining from use and devising management strategies to prevent relapse. ${ }^{26}$

\section{PST program for caregivers}

The PST program for the youths' caregivers also consisted of ten weekly, 120-minute sessions that were led by two senior consulting psychologists designated by the court. The said therapists assisted the caregivers in assessing their current relationship with their children, as well as their techniques with regard to influencing them. The therapists aided the participating caregivers to discover their negative family interaction patterns, in order to change them and, subsequently, their family's daily environment. Moreover, the therapists helped the caregivers improve their parenting of and communication with their teenaged children. The goal of this part of the program was to teach the caregivers of substanceusing youths more effective skills for handling problems related to their teenaged youths' substance abuse. ${ }^{27,28}$

\section{Study procedures and outcomes}

The participating youths' sociodemographic characteristics (eg, categories of substances being used, history of previous convictions, family status, and academic or social status) were provided by the Taiwan Kaohsiung Juvenile and Family Court. Once the course of treatment was completed, all participants were submitted to the supervision and probation of the court, which included notifying the protection officers of their academic, social, or living status approximately once a month. In the follow-up period, the adolescents had to provide urine samples to be tested for the presence of substances at the discretion of the judges or protection officers. If the aforementioned urine test came back positive, the court would detain the adolescent, who would then be either sentenced to participate in reformatory education or incarcerated in the detoxification unit of the detention center.
The primary outcome of this study was concerned with substance use relapse during the follow-up period. Relapse was defined as a positive urine test for any substance within the follow-up period. The secondary outcome consisted of the academic or social status at the end of the period. The academic or social outcome was categorized as attending school, being employed, and being a dropout/unemployed. Participants' records/information of relapse and academic or social status during the follow-up was also provided by the Taiwan Kaohsiung Juvenile and Family Court. The participants' records were followed-up through to December 31, 2015 or for a maximum of 2 years.

\section{Statistical analysis}

Data were analyzed in this study using the statistical software package Statistical Package for the Social Sciences, version 16.0 (SPSS Inc., Chicago, IL, USA). Variables are presented as either mean \pm standard deviation or frequency. A chi-square $\left(\chi^{2}\right)$ test or analysis of variance was used to compare variables between groups. A two-tailed $P$-value $<0.05$ was considered statistically significant.

Data analysis was based on the intention-to-treat principle. Every youth's index episode of substance use within the study period was used in the calculation of risk over time. Regarding survival analysis, the time function was calculated as the number of days from the index substance use to the end of the period for those youths who had no other instance of substance use to that point or otherwise until the date of relapse if it is prior to the end of the follow-up period. During the follow-up period, cumulative survival rates were expressed using Kaplan-Meier curves. Cox regression models and multivariate logistic regression models were developed to estimate the treatment effects on relapse in terms that control for sociodemographic variables. Both Cox regression models and logistic regression are widely used for analyzing the relationship between multiple risk factors and a time-related dichotomous event. ${ }^{29} \mathrm{We}$ entered all independent variables at the same time, and adjusted hazard ratios (aHRs) and adjusted odds ratios (aORs) were calculated with $95 \%$ confidence intervals (CIs).

As the academic or social outcomes were categorized into three groups (attending school, employed, and dropout/ unemployed), multinomial logistic regression was employed to examine the treatment's influence on academic or social outcomes, controlling for sociodemographic variables. The aOR with 95\% CI was calculated for each group.

\section{Results}

The present study included 121 participants (mean age: $16.1 \pm 1.1$ years). Ketamine was the most common substance 
Table I Sociodemographic characteristics at baseline of the three groups of adolescents with substance use who were investigated in this study

\begin{tabular}{|c|c|c|c|c|c|}
\hline Variables & $\begin{array}{l}\text { MEP group } \\
(n=36)\end{array}$ & $\begin{array}{l}\text { MEP + PST group } \\
(n=4 I)\end{array}$ & $\begin{array}{l}\text { Control group } \\
(n=44)\end{array}$ & $\begin{array}{l}\text { Statistical } \\
\text { value }\end{array}$ & $P$-value \\
\hline \multicolumn{6}{|l|}{ Age (years) } \\
\hline Range & $13-17$ & $13-17$ & $13-18$ & & \\
\hline Mean $(S D)$ & $16.3(0.9)$ & $16.0(1.2)$ & $16.1(1.1)$ & $F=0.73$ & 0.484 \\
\hline Sex, n (\%) & & & & $\chi^{2}=0.46$ & 0.795 \\
\hline Female & $9(25.0)$ & $8(19.5)$ & II (25.0) & & \\
\hline Male & $27(75.0)$ & $33(80.5)$ & $33(75.0)$ & & \\
\hline Substance abused, n (\%) & & & & $\chi^{2}=9.68$ & 0.075 \\
\hline Ketamine & $19(52.8)$ & $33(80.5)$ & $32(72.7)$ & & \\
\hline Methamphetamine & $12(33.3)$ & $6(14.6)$ & II (25.0) & & \\
\hline MDMA or others & $5(13.9)$ & $2(4.9)$ & $\mathrm{I}(2.3)$ & & \\
\hline Previous conviction record at baseline, $\mathrm{n}$ (\%) & & & & $\chi^{2}=2.83$ & 0.244 \\
\hline Without & $24(66.7)$ & $32(78.0)$ & $27(61.4)$ & & \\
\hline With & $12(33.3)$ & $9(22.0)$ & $17(38.6)$ & & \\
\hline Academic or social status at baseline, $\mathrm{n}(\%)$ & & & & $\chi^{2}=7.44$ & 0.116 \\
\hline Attending school & $9(25.0)$ & $16(39.0)$ & $14(3 \mid .8)$ & & \\
\hline Employed & $16(44.4)$ & $19(46.3)$ & $13(29.5)$ & & \\
\hline Dropout and unemployed & II (30.6) & $6(14.6)$ & $17(38.6)$ & & \\
\hline Family status, n (\%) & & & & $\chi^{2}=1.91$ & 0.754 \\
\hline Double-parent families & $13(36.1)$ & $18(43.9)$ & $13(29.5)$ & & \\
\hline Single-parent families & $16(44.4)$ & $16(39.0)$ & $22(50.0)$ & & \\
\hline Grandparent(s) & $7(19.4)$ & $7(17.1)$ & $9(20.5)$ & & \\
\hline
\end{tabular}

Notes: MEP group adolescents received MEP; MEP + PST group adolescents participated in an MEP program and their caregivers participated in a PST program; and standard supervision by the court served as the control group.

Abbreviations: MDMA, 3,4-methylenedioxy-methamphetamine; MEP, motivational enhancement psychotherapy; PST, parenting skills training; SD, standard deviation.

abused by the participating youths, followed by methamphetamine. With regard to academic or social status at baseline, $32.2 \%$ were attending school, 39.7\% were employed, and $28.1 \%$ had been suspended or had already dropped out from school. No significant differences were found in the sociodemographic characteristics among the three groups, that is, the MEP group, the MEP + PST group, and the control group, at baseline (Table 1).

Of the 121 participating youths, $40(33.1 \%)$ relapsed back into substance use in the follow-up period (Table 2), which consisted of 13 (36.1\%) from the MEP group, nine $(22.0 \%)$ from the MEP + PST group, and 18 (40.9\%) from the control group. Figure 1 shows the Kaplan-Meier curves of relapse during the follow-up period categorized into treatment groups. The multivariate logistic regression model (Table 3 ) reveals that the probability of relapse in the MEP group resembled that of the control group $(\mathrm{aOR}=0.89, P=0.802)$. However, the probability of relapse in the MEP + PST group was marginally lower than that of the control group $(\mathrm{aOR}=0.37, P=0.052)$. The adjusted Cox proportional hazard model resulted in similar findings (Table 3). This model also showed that the probability of relapse did not differ significantly between

Table 2 Outcomes of the three groups of adolescents with substance use during the follow-up period

\begin{tabular}{|c|c|c|c|c|c|}
\hline Variables & $\begin{array}{l}\text { MEP group } \\
(n=36) n(\%)\end{array}$ & $\begin{array}{l}\text { MEP + PST group } \\
(n=4 I) n(\%)\end{array}$ & $\begin{array}{l}\text { Control group } \\
(n=44) n(\%)\end{array}$ & $\begin{array}{l}\text { Statistical } \\
\text { value }\end{array}$ & $P$-value \\
\hline Relapse & & & & $\chi^{2}=3.66$ & 0.148 \\
\hline Yes & $13(36.1)$ & $9(22.0)$ & $18(40.9)$ & & \\
\hline No & $23(63.9)$ & $32(78.0)$ & $26(59.1)$ & & \\
\hline $\begin{array}{l}\text { Academic or social status at } \\
\text { the endpoint }\end{array}$ & & & & $\chi^{2}=18.79$ & $0.00 I^{*}$ \\
\hline Attending school & $12(33.3)$ & $17(4 \mid .5)$ & II (25.0) & & \\
\hline Employed & $18(50.0)$ & $19(46.3)$ & II (25.0) & & \\
\hline Dropout and unemployed & $6(16.7)$ & $5(12.2)$ & $22(50.0)$ & & \\
\hline
\end{tabular}

Notes: MEP group adolescents received MEP; MEP + PST group adolescents participated in an MEP program and their caregivers participated in a PST program; and standard supervision by the court served as the control group. ${ }^{*} P<0.05$.

Abbreviations: MEP, motivational enhancement psychotherapy; PST, parenting skills training. 


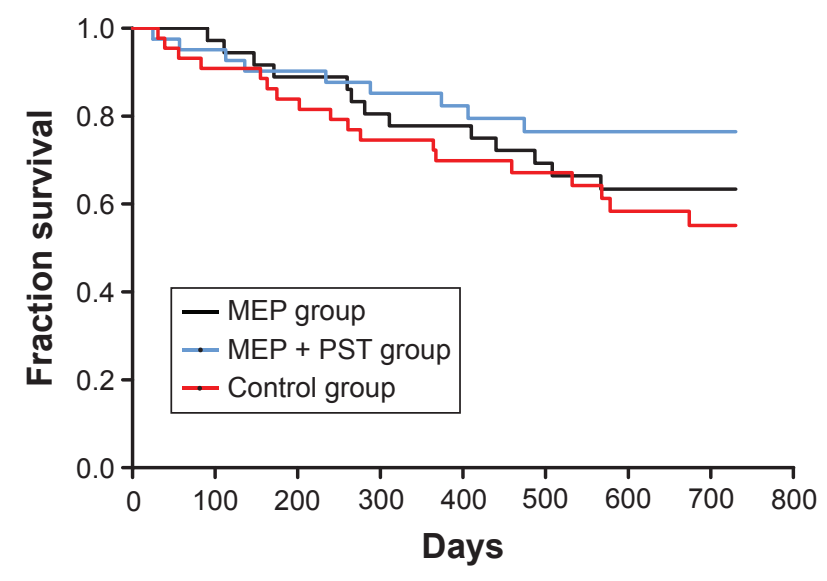

Figure I Kaplan-Meier curves of substance use relapse during the follow-up period categorized into three treatment groups.

Notes: MEP group adolescents received MEP; MEP + PST group adolescents participated in an MEP program and their caregivers participated in a PST program; and standard supervision by the court served as the control group.

Abbreviations: MEP, motivational enhancement psychotherapy; PST, parenting skills training.

the MEP and control groups ( $\mathrm{aHR}=0.82, P=0.600$ ) and that the MEP + PST group had a marginally lower risk of relapse than the control group ( $\mathrm{aHR}=0.48, P=0.077$ ). No baseline sociodemographic characteristics were able to significantly predict the rates of relapse.
At the end of the follow-up period (Table 2), academic or social outcome differed significantly among the groups $\left(\chi^{2}=18.79, P=0.001\right)$. Of the three groups, adolescents in the control group had the lowest rate of attending school $(25 \%)$ or being employed (25\%), while having the highest rate $(50 \%)$ of having dropped out from school or being unemployed. Table 4 shows the OR of variables of academic or social outcomes using the multinomial logistic regression model. The MEP group $(\mathrm{aOR}=6.61, P=0.009)$ and $\mathrm{MEP}+\mathrm{PST}$ group ( $\mathrm{aOR}=8.57, P=0.005$ ), as well as the youths who were attending school at the baseline ( $\mathrm{aOR}=11.32, P=0.002)$ were more likely to be attending school at the end of the study period. Similarly, the MEP group $(\mathrm{aOR}=7.75, P=0.004)$, MEP + PST group $(\mathrm{aOR}=7.27, P=0.006)$, and youths who were already employed at the baseline $(\mathrm{aOR}=8.37, P=0.001)$ were significantly linked with employment at the end of the study.

\section{Discussion}

This study offers support for the long-term effectiveness of a family-oriented group treatment program for adolescents addicted to substance use and for their caregivers. Youths who participated in a treatment program that combined MEP and PST were found to have a lower relapse rate than those youths

Table 3 Risk of relapse $(n=40)$ after the index substance use for related variables estimated by multivariate logistic regression model and Cox proportional hazards model

\begin{tabular}{|c|c|c|c|c|c|}
\hline \multirow[t]{2}{*}{ Variables } & \multirow{2}{*}{$\frac{\text { Relapse }}{\text { n/N (\%) }}$} & \multicolumn{2}{|c|}{ Logistic regression model } & \multicolumn{2}{|c|}{ Cox regression model } \\
\hline & & aOR (95\% CI) & $P$-value & $\operatorname{aHR}(95 \% \mathrm{Cl})$ & $P$-value \\
\hline \multicolumn{6}{|l|}{ Treatment group } \\
\hline MEP group & I3/36 (36.1) & $0.89(0.34-2.30)$ & 0.802 & $0.82(0.39-1.72)$ & 0.600 \\
\hline MEP + PST group & $9 / 4 I(22.0)$ & $0.37(0.14-1.01)$ & 0.052 & $0.48(0.21-1.09)$ & 0.077 \\
\hline Control group & I8/44 (40.9) & I & & I & \\
\hline Age (years) & & $1.13(0.76-1.68)$ & 0.543 & $1.09(0.80-1.50)$ & 0.577 \\
\hline \multicolumn{6}{|l|}{ Sex } \\
\hline Male & $32 / 93(34.4)$ & $1.19(0.44-3.22)$ & 0.738 & I.II (0.50-2.48) & 0.801 \\
\hline Female & $8 / 28(28.6)$ & 1 & & 1 & \\
\hline \multicolumn{6}{|l|}{ Substance use } \\
\hline Ketamine & $30 / 84(35.7)$ & $1.49(0.58-3.78)$ & 0.405 & $1.30(0.59-2.85)$ & 0.518 \\
\hline Other substance & I0/37 (27.0) & I & & I & \\
\hline \multicolumn{6}{|l|}{ Previous conviction record } \\
\hline Without & $25 / 83(30.1)$ & $0.74(0.32-1.73)$ & 0.487 & $0.75(0.39-1.44)$ & 0.388 \\
\hline With & I5/38 (39.5) & 1 & & I & \\
\hline \multicolumn{6}{|l|}{ Academic or social status } \\
\hline Attending school & I6/39 (4I.0) & $2.12(0.70-6.44)$ & 0.186 & $\mathrm{I} .69(0.7 \mathrm{I}-4.0 \mathrm{I})$ & 0.236 \\
\hline Employed & I4/48 (29.2) & $1.22(0.44-3.40)$ & 0.700 & $1.19(0.5 \mathrm{I}-2.77)$ & 0.687 \\
\hline Dropout and unemployed & I0/34 (29.4) & I & & I & \\
\hline \multicolumn{6}{|l|}{ Family status } \\
\hline Double-parent families & I5/44 (34.I) & $1.00(0.32-3.09)$ & 0.997 & $1.07(0.44-2.56)$ & 0.888 \\
\hline Single-parent families & $17 / 54(31.5)$ & $0.85(0.29-2.50)$ & 0.770 & I.0I (0.43-2.36) & 0.982 \\
\hline Grandparent(s) & $8 / 23(34.8)$ & I & & 1 & \\
\hline
\end{tabular}

Notes: $\mathrm{n}$ refers to number of individuals who relapsed with substance use; $\mathrm{N}$ refers to total number of subjects.

Abbreviations: aHR, adjusted hazard ratio; aOR, adjusted odds ratio; $\mathrm{Cl}$, confidence interval; MEP, motivational enhancement psychotherapy; PST, parenting skills training. 
Table 4 Odds ratio of variables of academic or social outcomes by multinomial logistic regression model

\begin{tabular}{|c|c|c|c|c|c|c|c|}
\hline \multirow[t]{2}{*}{ Variables } & \multirow{2}{*}{$\begin{array}{l}\text { Attending } \\
\text { school }^{a}(n=40) \\
n(\%)\end{array}$} & \multirow{2}{*}{$\begin{array}{l}\begin{array}{l}\text { Employed }^{a} \\
(n=48)\end{array} \\
n(\%)\end{array}$} & \multirow{2}{*}{$\begin{array}{l}\begin{array}{l}\text { Dropout/unemployed } \\
(\mathrm{n}=33)\end{array} \\
\mathrm{n}(\%)\end{array}$} & \multicolumn{2}{|c|}{$\begin{array}{l}\text { Attending school versus } \\
\text { dropout/unemployed }\end{array}$} & \multicolumn{2}{|c|}{$\begin{array}{l}\text { Employed versus } \\
\text { dropout/unemployed }\end{array}$} \\
\hline & & & & aOR $(95 \% \mathrm{Cl})$ & $P$-value & aOR $(95 \% \mathrm{Cl})$ & $P$-value \\
\hline \multicolumn{8}{|l|}{ Treatment group } \\
\hline MEP group & $12(30.0)$ & $18(37.5)$ & $6(18.2)$ & $6.61(1.60-27.35)$ & $0.009 *$ & 7.75 (1.95-30.75) & $0.004^{*}$ \\
\hline MEP + PST group & $17(42.5)$ & $19(39.6)$ & $5(15.2)$ & $8.57(1.94-37.82)$ & $0.005^{*}$ & 7.27 (1.76-29.97) & $0.006^{*}$ \\
\hline Control group & II (27.5) & II (22.9) & $22(66.7)$ & 1 & & I & \\
\hline Age (years) & & & & $1.28(0.75-2.19)$ & 0.367 & $1.09(0.61-1.92)$ & 0.789 \\
\hline \multicolumn{8}{|l|}{ Sex } \\
\hline Male & $33(82.5)$ & $36(75.0)$ & $24(72.7)$ & $\mathrm{I} .03(0.27-4.0 \mathrm{I})$ & 0.965 & $0.72(0.20-2.66)$ & 0.621 \\
\hline Female & $7(17.5)$ & $12(25.0)$ & $9(27.3)$ & I & & 1 & \\
\hline \multicolumn{8}{|l|}{ Substance use } \\
\hline Ketamine & $31(77.5)$ & $32(66.7)$ & $21(63.6)$ & $1.30(0.37-4.50)$ & 0.682 & $1.87(0.57-6.18)$ & 0.304 \\
\hline Other substance & $9(22.5)$ & $16(33.3)$ & $12(36.4)$ & I & & I & \\
\hline \multicolumn{8}{|l|}{ Previous conviction } \\
\hline Without & $30(75.0)$ & $33(68.8)$ & $20(60.6)$ & $1.54(0.46-5.14)$ & 0.486 & $0.91(0.29-2.83)$ & 0.868 \\
\hline With & $10(25.0)$ & $15(31.2)$ & $13(39.4)$ & I & & 1 & \\
\hline \multicolumn{8}{|l|}{ Academic or social status ${ }^{b}$} \\
\hline Attending school & $26(65.0)$ & $7(14.6)$ & $6(18.2)$ & II.32 (2.46-52.06) & $0.002^{*}$ & $3.60(0.67-19.43)$ & 0.136 \\
\hline Employed & $5(12.5)$ & $34(70.8)$ & $9(27.3)$ & $0.78(0.18-3.48)$ & 0.745 & $8.37(2.32-30.20)$ & $0.00 I^{*}$ \\
\hline Dropout and unemployed & $9(22.5)$ & $7(14.6)$ & I8 (54.5) & 1 & & I & \\
\hline \multicolumn{8}{|l|}{ Family status } \\
\hline Double-parent families & $14(35.0)$ & $17(35.4)$ & $13(39.4)$ & $0.69(0.15-3.17)$ & 0.632 & $0.86(0.19-3.81)$ & 0.838 \\
\hline Single-parent families & $19(47.5)$ & $23(47.9)$ & $12(36.4)$ & $2.0 \mathrm{I}(0.45-9.0 \mathrm{I})$ & 0.364 & $2.30(0.52-10.23)$ & 0.275 \\
\hline Grandparent(s) & 7 (I7.5) & $8(16.7)$ & $8(24.2)$ & I & & I & \\
\hline
\end{tabular}

Notes: ${ }^{a}$ Academic and social status at the endpoint of this study; bacademic and social status at baseline. $* P<0.05$.

Abbreviations: $\mathrm{aOR}$, adjusted odds ratio; $\mathrm{Cl}$, confidence interval; MEP, motivational enhancement psychotherapy; PST, parenting skills training.

in the control group. In comparison with the control group, both the MEP + PST group and the MEP group had better academic or social outcomes by the end of the follow-up period.

\section{Substance use relapse}

Of all the participants, $33.1 \%$ relapsed during the follow-up period. Substance use relapse was defined by a conviction due to a positive urine test result. We also reasonably assumed that a number of adolescents who had relapsed with a substance avoided detection from the urine tests carried out by the court. Therefore, the actual relapse rate of substance use may possibly be higher than the relapse rate detected in this study. This finding suggests that breaking the drug addiction cycle for substance-using adolescents remains a challenge. However, we found that a combined treatment program of MEP and PST would be advantageous in preventing relapse among adolescents using illegal substances.

MEP's purpose is to encourage youths to stop using drugs. Involving youths' caregivers helps such treatment to be beneficial when also dealing with their family's function. The goal of the PST program is to teach youths' caregivers more effective skills for handling the problems related to their children's substance abuse. ${ }^{17}$ Being the parent of an adolescent these days involves the immense challenge of not only promoting the adolescent's development of life skills, but also helping them to make smart choices, like saying no to drugs. ${ }^{30}$ Effective parenting should consist of communication, consistency, and safety-based boundaries, as well as being aware of the adolescents' friends and activities. ${ }^{31}$ The PST program empowers parents to deter and even detect their adolescents' substance use, as well as to facilitate their children to stop using illegal substances, start recovery, and sustain sobriety. ${ }^{27}$ Previous randomized trials have shown that family-based therapy outperformed nonfamily treatment in improving delinquency and reducing alcohol and drug use among substance-using youths. ${ }^{28,32}$ The present study's finding is generally consistent with these results. We found that combining MEP and PST programs can enhance participants' family function and further prevent relapse of substance use, even more than the MEP program alone.

Although no significant differences were found in the baseline characteristics among the groups, a selection bias, derived from the nonrandomized and open-label procedure, most likely influenced the study results. For example, the majority of adolescents in the MEP + PST group participated in this program after their first offense (78\%). In contrast, the control group had the highest proportion of adolescents with a record of a preexisting conviction (38.6\%). This finding 
suggests that the control group participants may have had a more severe drug addiction and, thus, less motivation to reform, and were less likely to be referred by the court judges to participate in the treatment program. Therefore, a randomized control study will be needed in the future to verify that the MEP + PST program actually has a long-term preventive influence on substance use relapse.

\section{Academic or social status}

In comparison with the control group, both the MEP group and the MEP + PST group showed higher rates of attending school or being employed at the end of the study period. Adolescents with illicit drug use also often have psychiatric illnesses and serious behavioral problems. ${ }^{33}$ Such adolescents have a high risk of dropping out of school, social maladjustment, and impairments in occupational function. ${ }^{34,35}$ The goal of MEP programs is to arouse the youths' motivation for change by discovering their reasons for using illegal substances, as well as their reasons for abstaining. ${ }^{16}$ During the MEP process, the participating adolescents may also be encouraged to change their lifestyles, thus further contributing to the long-term benefits of their social-occupational functioning. ${ }^{15}$ The findings of this study suggest that the MEP program not only improves youths' motivation to abstain from drug use, but also increases their likelihood to stay in school or look for/maintain their jobs.

We found that the baseline academic and social status also served as a preview for the corresponding status at this study's endpoint. The individuals attending school or holding a job already maintained that status through the end of the follow-up period. In contrast, those who had already dropped out of school or were unemployed at the beginning may have exhibited poor academic and social achievement, and it was likely that their dropout/unemployed status was maintained throughout the follow-up period.

\section{Limitations and strengths}

This study has several limitations. First, this study had a small sample size, which reduces its ability to detect potential benefits of the treatment program, as well as limits its capability to definitively identify outcome-associated factors. As a result, some of the negative findings or marginal statistical values in this study may actually be the result of inadequate statistical power. Second, this study was conducted using nonrandomized and open-label methods, so the results could be unwittingly influenced by selection bias. In addition, there was no blinding of outcome assessment and data analysis; thus, the result was likely to be influenced by detection bias. Third, all the participants of the three different groups were not recruited during the same time frame. Compared to the participants in the MEP group, adolescents in the MEP + PST group were recruited later and, thus, may have a shorter follow-up period ( $<2$ years). This factor may favorably influence the relapse rate results in the MEP + PST group. Finally, several additional factors that may have potentially influenced the severity of the drug addiction and the study's outcomes were not identified, such as peer relationships, ${ }^{36}$ intelligence or academic performance, ${ }^{37}$ and psychiatric comorbidities. ${ }^{33}$ Therefore, whether these factors affected the results of this study is uncertain.

Despite its limitations, this study has some definite strengths. First, we maintain that we are the foremost in providing evidence with regard to the long-term outcomes of a combined treatment program for both substance-using youths and their caregivers. Second, compared to previous studies that used self-administered questionnaires to determine the major outcomes, ${ }^{38}$ this study uses outcome measures that are generally objective and reliable.

\section{Conclusion}

This study shows that a family-oriented treatment program with MEP for substance-using youths and PST for their caregivers can be effective for the long-term prevention of relapses. Compared to adolescents who only received standard court supervision, those who received group psychotherapy based on the MEP principle had better school attendance or social outcomes over the course of follow-up. However, further research with larger sample sizes and a randomized control method are needed in the future to verify whether the types of treatment program for adolescents, in fact, influence their substance use relapses and academic or social outcomes.

\section{Acknowledgments}

LJW and SFL are joint first authors and contributed equally to this manuscript. The authors would like to thank MingHsiung Liu, Yung-Hsuan Lee, and the staff of Taiwan Kaohsiung Juvenile and Family Court, as well as all the patients who participated in this study. This study was funded by a grant from Chang Gung Memorial Hospital (CMRPG8C1091).

\section{Disclosure}

The authors report no conflicts of interest in this work.

\section{References}

1. Merikangas KR, McClair VL. Epidemiology of substance use disorders. Hum Genet. 2012;131(6):779-789.

2. Monasterio EB. Adolescent substance involvement use and abuse. Prim Care. 2014;41(3):567-585. 
3. Feinstein EC, Richter L, Foster SE. Addressing the critical health problem of adolescent substance use through health care, research, and public policy. J Adolesc Health. 2012;50(5):431-436.

4. Park MJ, Scott JT, Adams SH, Brindis CD, Irwin CE Jr. Adolescent and young adult health in the United States in the past decade: little improvement and young adults remain worse off than adolescents. J Adolesc Health. 2014;55(1):3-16.

5. Chou P, Liou MY, Lai MY, Hsiao ML, Chang HJ. Time trend of substance use among adolescent students in Taiwan, 1991-1996. J Formos Med Assoc. 1999;98(12):827-831.

6. Hsu LY. Ketamine use in Taiwan: Moral panic, civilizing processes, and democratization. Int J Drug Policy. 2014;25(4):819-822.

7. Chen WJ, Fu TC, Ting TT, et al. Use of ecstasy and other psychoactive substances among school-attending adolescents in Taiwan: national surveys 2004-2006. BMC Public Health. 2009;9:27.

8. Chen YT, Chen CY, Chen WJ. Comparative epidemiology of betel nut use versus ecstasy use among Taiwanese adolescents: findings from a national survey. Drug Alcohol Depend. 2011;113(2-3):177-183.

9. Whiteford HA, Degenhardt L, Rehm J, et al. Global burden of disease attributable to mental and substance use disorders: findings from the Global Burden of Disease Study 2010. Lancet. 2013;382(9904):1575-1586.

10. Ferrari AJ, Norman RE, Freedman G, et al. The burden attributable to mental and substance use disorders as risk factors for suicide: findings from the Global Burden of Disease Study 2010. PLoS One. 2014;9(4):e91936.

11. Patnode CD, O'Connor E, Rowland M, Burda BU, Perdue LA, Whitlock EP. Primary care behavioral interventions to prevent or reduce illicit drug use and nonmedical pharmaceutical use in children and adolescents: a systematic evidence review for the U.S. Preventive Services Task Force. Ann Intern Med. 2014;160(9):612-620.

12. Hogue A, Henderson CE, Ozechowski TJ, Robbins MS. Evidence base on outpatient behavioral treatments for adolescent substance use: updates and recommendations 2007-2013. J Clin Child Adolesc Psychol. 2014; 43(5):695-720.

13. Waldron HB, Turner CW. Evidence-based psychosocial treatments for adolescent substance abuse. J Clin Child Adolesc Psychol. 2008;37(1): 238-261.

14. Winters KC, Tanner-Smith EE, Bresani E, Meyers K. Current advances in the treatment of adolescent drug use. Adolesc Health Med Ther. 2014;5: 199-210.

15. Bukstein OG, Horner MS. Management of the adolescent with substance use disorders and comorbid psychopathology. Child Adolesc Psychiatr Clin N Am. 2010;19(3):609-623.

16. Tevyaw TO, Monti PM. Motivational enhancement and other brief interventions for adolescent substance abuse: foundations, applications and evaluations. Addiction. 2004;99 Suppl 2:63-75.

17. Williams JF, Burton RS, Warzinski SS. The role of the parent in adolescent substance use. Pediatr Ann. 2014;43(10):410.

18. Kamon JL, Stanger C, Budney AJ, Dumenci L. Relations between parent and adolescent problems among adolescents presenting for family-based marijuana abuse treatment. Drug Alcohol Depend. 2006; 85(3):244-254.

19. Hummel A, Shelton KH, Heron J, Moore L, van den Bree MB. A systematic review of the relationships between family functioning, pubertal timing and adolescent substance use. Addiction. 2013;108(3):487-496.

20. Calafat A, Garcia F, Juan M, Becona E, Fernandez-Hermida JR. Which parenting style is more protective against adolescent substance use? Evidence within the European context. Drug Alcohol Depend. 2014;138:185-192.
21. Galanter M, Glickman L, Singer D. An overview of outpatient treatment of adolescent substance abuse. Subst Abuse. 2007;28(2):51-58.

22. Tanner-Smith EE, Wilson SJ, Lipsey MW. The comparative effectiveness of outpatient treatment for adolescent substance abuse: a metaanalysis. J Subst Abuse Treat. 2013;44(2):145-158.

23. Engle B, Macgowan MJ. A critical review of adolescent substance abuse group treatments. J Evid Based Soc Work. 2009;6(3):217-243.

24. Kaminer Y. Challenges and opportunities of group therapy for adolescent substance abuse: a critical review. Addict Behav. 2005;30(9): 1765-1774.

25. Narcotics Hazard Prevention Act [webpage on the Internet]. Laws \& Regulations Database of The Republic of China; 2015 [cited February 12, 2016]. Available from: http://law.moj.gov.tw/Eng/LawClass/ LawContent.aspx?PCODE=C0000008. Accessed Feb 4, 2015.

26. Walker DD, Stephens R, Roffman R, et al. Randomized controlled trial of motivational enhancement therapy with nontreatment-seeking adolescent cannabis users: a further test of the teen marijuana check-up. Psychol Addict Behav. 2011;25(3):474-484.

27. McGillicuddy NB, Rychtarik RG, Duquette JA, Morsheimer ET. Development of a skill training program for parents of substance-abusing adolescents. J Subst Abuse Treat. 2001;20(1):59-68.

28. Liddle HA, Rowe CL, DakofGA, Ungaro RA, Henderson CE. Early intervention for adolescent substance abuse: pretreatment to posttreatment outcomes of a randomized clinical trial comparing multidimensional family therapy and peer group treatment. J Psychoactive Drugs. 2004; 36(1):49-63.

29. Annesi I, Moreau T, Lellouch J. Efficiency of the logistic regression and Cox proportional hazards models in longitudinal studies. Stat Med. 1989;8(12):1515-1521.

30. Baldwin SA, Christian S, Berkeljon A, Shadish WR. The effects of family therapies for adolescent delinquency and substance abuse: a meta-analysis. J Marital Fam Ther. 2012;38(1):281-304.

31. McGillicuddy NB, Rychtarik RG, Papandonatos GD. Skill training versus 12-step facilitation for parents of substance-abusing teens. J Subst Abuse Treat. 2015;50:11-17.

32. Hogue A, Dauber S, Henderson CE, et al. Randomized trial of family therapy versus nonfamily treatment for adolescent behavior problems in usual care. J Clin Child Adolesc Psychol. 2015;44(6):954-969.

33. Riggs P, Levin F, Green AI, Vocci F. Comorbid psychiatric and substance abuse disorders: recent treatment research. Subst Abus. 2008; 29(3):51-63.

34. Briere FN, Fallu JS, Morizot J, Janosz M. Adolescent illicit drug use and subsequent academic and psychosocial adjustment: an examination of socially-mediated pathways. Drug Alcohol Depend. 2014;135:45-51.

35. Henry KL, Knight KE, Thornberry TP. School disengagement as a predictor of dropout, delinquency, and problem substance use during adolescence and early adulthood. J Youth Adolesc. 2012;41(2):156-166.

36. Lee KH, Yeh YC, Yang PC, et al. Individual and peer factors associated with ketamine use among adolescents in Taiwan. Eur Child Adolesc Psychiatry. 2012;21(10):553-558.

37. Fletcher A, Bonell C, Hargreaves J. School effects on young people's drug use: a systematic review of intervention and observational studies. J Adolesc Health. 2008;42(3):209-220.

38. Kaminer Y. Adolescent substance abuse treatment: evidence-based practice in outpatient services. Curr Psychiatry Rep. 2002;4(5):397-401.

\section{Dovepress}

\section{Publish your work in this journal}

Neuropsychiatric Disease and Treatment is an international, peerreviewed journal of clinical therapeutics and pharmacology focusing on concise rapid reporting of clinical or pre-clinical studies on a range of neuropsychiatric and neurological disorders. This journal is indexed on PubMed Central, the 'PsycINFO' database and CAS,

and is the official journal of The International Neuropsychiatric Association (INA). The manuscript management system is completely online and includes a very quick and fair peer-review system, which is all easy to use. Visit http://www.dovepress.com/testimonials.php to read real quotes from published authors. 